\title{
AUTOMATIC OIL LEAK DETECTION CONVEYED OVER GSM
}

\section{R.SUNDAR}

Assistant Professor, Department of EEE Marine, AMET University, Chennai, Tamil Nadu, India

Environmental and individual well-being issues have created the need for more efficient leak detection and location on oil pipelines. For organizations working these pipelines a leak, regardless of how unimportant it may appear, can bring about significant liabilities. As such, pipes operators are increasingly concerned with monitoring the performance of pipes that are becoming fatigued and outdated. This is a useful and straightforward security alarm system that can monitor an industry. This oil leakage sensor is easily available and can be interfaced with the microcontroller, with one of its many applications are in different offices and shops for security against leakage. The detector will sense leakage caused by any failure and prevent significant damage. The aim of this project is to monitor for oil leakage to avoid accidents providing industry safety feature where security has been a significant issues. When the system detects the oil leakage using IR pair sensor then immediately sends an alert to authorized mobile number through GSM.
\end{abstract}

KEYWORDS: GSM; IR Pair Sensor; Microcontroller; SMS

Received: Oct 06, 2017; Accepted: Oct 26, 2017; Published: Jan 30, 2018; Paper Id.: IJMPERDFEB2018100

\section{INTRODUCTION}

Oil Leakage is the major problem happening in household and industries. It will occur at any time around the areas covered by the pipeline network represented by (Veerakumar, 2017). This can cause environmental pollution and public health issues. Oil theft largely depends on the economy of the nation. Throughout the years (Mangai), there is a demand for a framework that will ensure safe conveyance and necessities for the transportation of fluids and gasses. The liquids and gasses might be unrefined petroleum, flammable gas, melted gas, petrochemical items, water and other fluid or vaporous items. This (Adikesavalu, 2016) paper demonstrates mechanized pipeline spillage framework, which can ready to screen the information. This structure utilizes the sensor to test the honesty of oil pipelines for the break (Olugboji, 2011). The framework offers affectability and positional precision outline. It works utilizing sensor with no mind-boggling parts; no power is expected to work the sensor along the pipeline course. Low power 128 point split-radix FFT for LTE application has been explained (Shilpha, 2015).

\section{Methodology Used}

In the initial step, the oil leakage is detected by the IR pair sensor. This detects the oil leakage and gives the signal to the microcontroller with the help of ADC. 


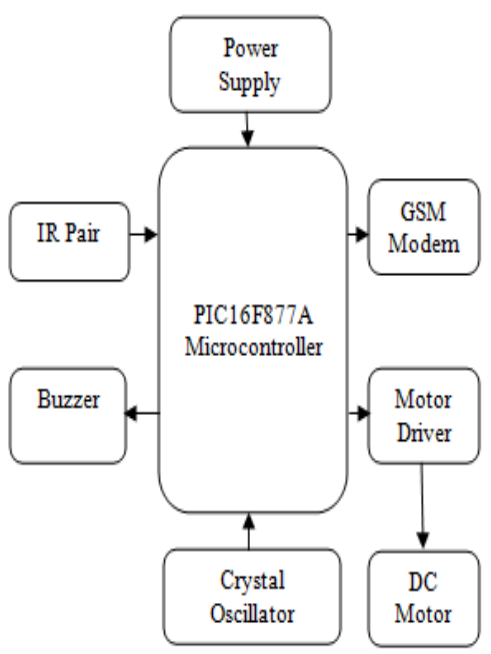

Figure 1: Block Diagram of Oil Leakage Detection and Security System

After that in the second step, the microcontroller receives the signal, send by IR pair sensor. It sends an initiation signal to other outside devices joined with it. For example, DC motor IC (L293D Motor Driver), buzzer, GSM module.

In the last step, many tasks have been performed, for example, bell actuates at the same time GSM module initiated, which send cautioning SMS to determined portable number and alarm the people at Industries by enacting the alert which incorporates the LED and Buzzer all the while to make the essential move and control the DC motor.

\section{MICROCONTROLLER}

The microcontroller is an advancement of innovation of integrated circuits. It can store a huge number of transistors into one chip. PIC16F877A were made by including outer peripherals, for example, memory, input-output lines and clocks. These incorporated circuits contained both processor and peripherals with five ports and are based on universal receiver and transmitter concept (USART). It has totally 40 pins from that only 33 pins are configured as an input-output pin. It can operate at $20 \mathrm{MHz}$ of the clock input. The device also has two serial communication ports.

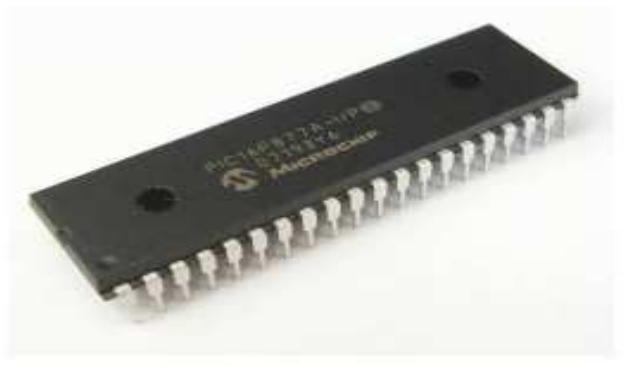

Figure 2: Pic16f877a Microcontroller

It operates on a 5V DC supply with the programmable code protection. The IC operates on a power supply voltage of 2 to $5.5 \mathrm{~V}$. It has a facility to reprogram.

\section{IR PAIR SENSOR}

An infrared sensor is a sensor used to detect certain qualities of its surroundings by discharging infrared radiation. Infrared sensors are likewise fit for measuring the warmth being transmitted by an object and identifying movement. 


\section{GSM MODEM}

A GSM modem is a wireless modem to communicate from one place to another place wirelessly. GSM modem sends and receives data through radio waves. It is interfaced with the microcontroller through the serial interface unit.

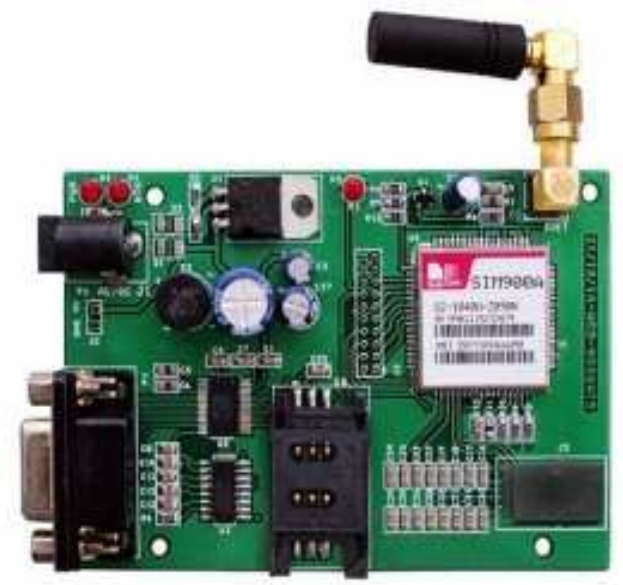

Figure 3: GSM Modem

The GSM module utilized as a part of this arrangement is an officially made module and was interfaced with the microcontroller through the serial interface unit. The SIM900 GSM module is used in this project.

\section{L293D MOTOR DRIVER}

The motor driver is a current improving Switching Device. Thus we insert motor driver in between motor and microcontroller. The input signal is given from microcontroller to the Motor driver take, and corresponding output will be produced.

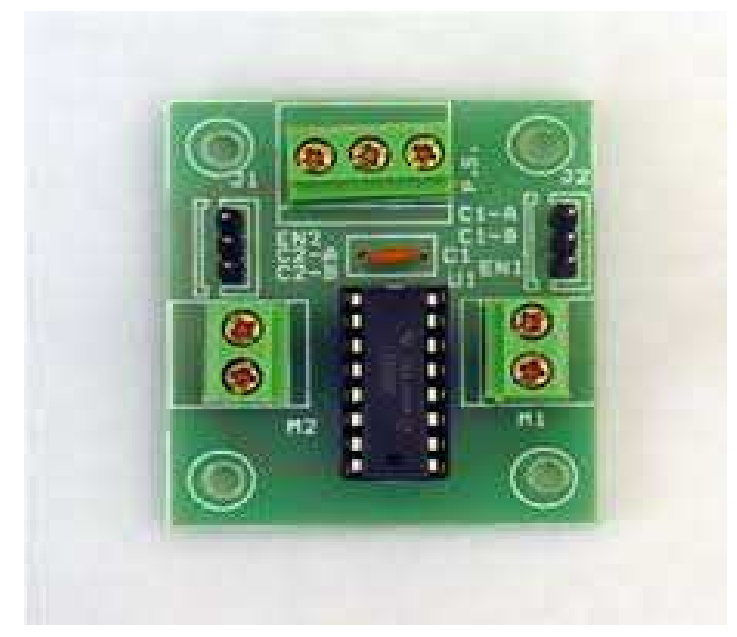

Figure 4: L293D Motor Driver

This is a motor driver IC that can drive two motors simultaneously. L293D IC is a dual H-bridge motor driver IC. One H-bridge is capable of driving a dc motor in bidirectional. L293D IC is a current enhancing IC as the output from the sensor is not able to drive motors itself, so L293D is used for this purpose. L293D is a 16 pin IC having two enables pins which should always remain high to enable both the H-bridges. 


\section{RESULTS}

The prototype of the oil leakage security system has been shown in figure 5. This system has been tested by blocking IR pair sensor. IR pair detects the oil leakage and sends a signal to the microcontroller. After that microcontroller sends an alert signal to other remotely associated devices As a result of a buzzer ring, simultaneously oil supply turns off with the help of DC motor and GSM module send an SMS. When the reset button is pressed, the system refreshes itself, and entire system recovers its initial position.

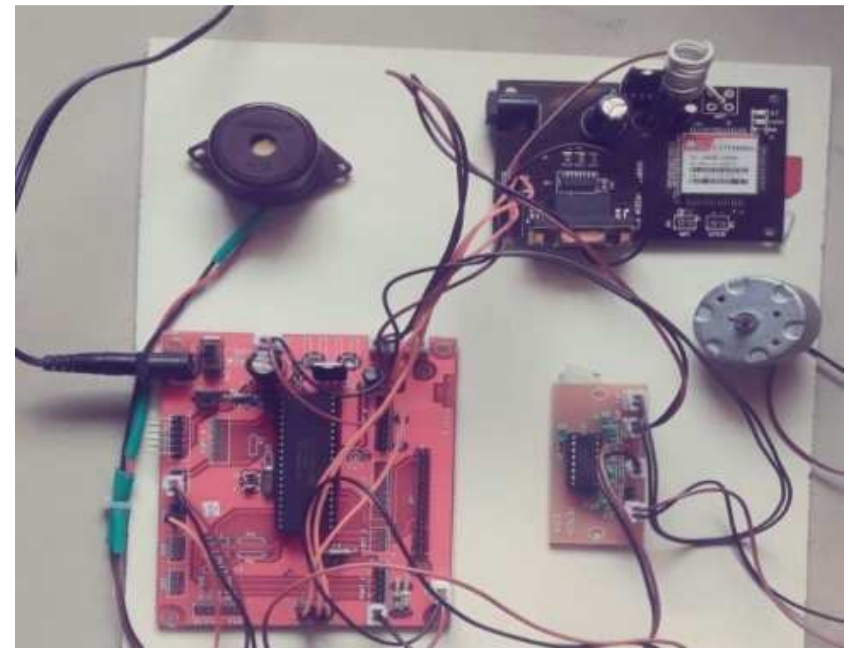

Figure 5: Prototype of the Oil Leakage Security System
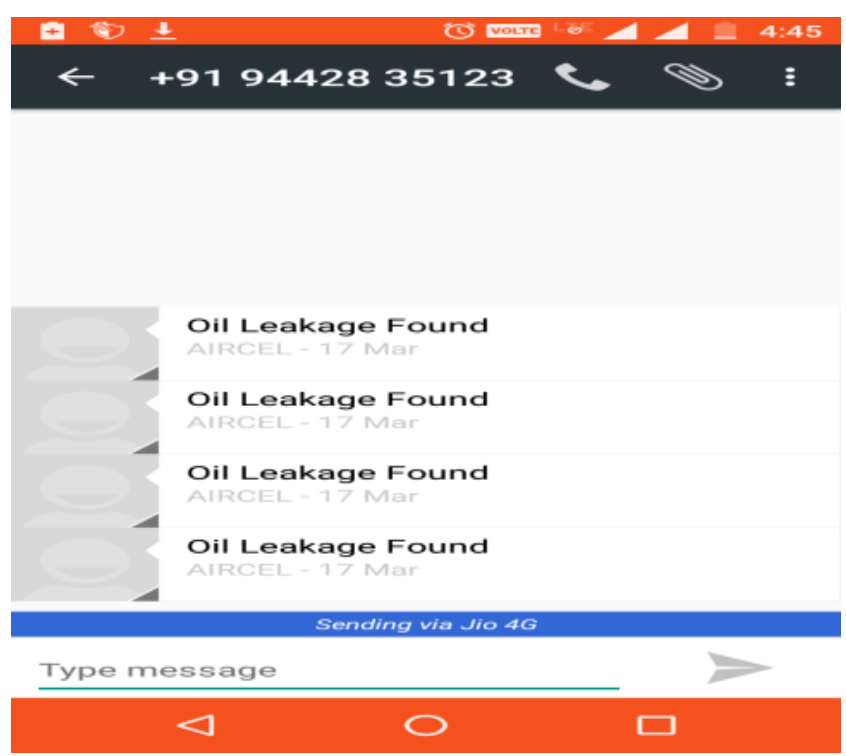

Figure 6: SMS Alert of Oil Leakage Security System

\section{CONCLUSIONS}

Oil leakages in households and industries cause risk to life and property. A tremendous misfortune must be brought about for the mischance happened by such spillages. A solution to such an issue is to set up a monitoring system which continues observing the spillage of oil and protects the consumer from such accidents. The present paper gives a solution to prevent such accidents by not only monitoring the system but by also turning off the oil supplies in case of a leakage. In addition to this, it activates an alarm as well as sends a message to the user. 


\section{REFERENCES}

1. Veerakumar, P., Dheepak, M., Saravanan, S.V., (2017). PLC based automatic control for an onboard ship gangway conveyor system, International Journal of Mechanical Engineering and Technology, 8(3), 229-235.

2. Mangai, K.A., Selvi, K.T., Priya, M., Rathnakumari, M., Sureshkumar, P. and Sagadevan, S., Investigations on dielectric and impedance properties of M-type hexaferrite. Journal of Materials Science: Materials in Electronics, 1-13.

3. Dahlan RP Sitompul \& Lince Tomoria Sianturi, Designing of Microcontroller 8051 Based Learning Media of Control by Using the MCU 8051 IDE and C Programming Language with a C-Compiler of SDCC-Small Device C Compiler to Support the Implementation of Active Learning in Higher Education-ALFHE (Active Learning for Higher Education), International Journal of Electronics, Communication \& Instrumentation Engineering Research and Development (IJECIERD), Volume 4, Issue 2, March - April 2014, pp. 107-112

4. Adikesavalu, H., Paul, P., Priyadarsani, L., Banerjee, S., Joardar, S.N. and Abraham, T.J., (2016). Edwardsiella tarda induces dynamic changes in immune effector activities and an endocrine network of Pangasius pangasius (Hamilton, 1822). Aquaculture, 462,24-29.

5. Olugboji, O. A. (2011). “Development of An Impact Monitoring System for Petroleum Pipelines,” United Kingdom.

6. Shilpha G. (2014) “Low power 128 point split-radix FFT for lte application”, International Journal of MC square Scientific Research (IJMSR).6(1),66-74. 
